\title{
Sistem Pendukung Kepututusan Menentukan Kriteria Dosen Terbaik Di Sekolah Tinggi Teknologi Muhammadiyah Cileungsi Metode Simple Additive Weighting
}

\author{
Nurkholis $^{1}$, Pria Sukamto ${ }^{2}$, Siswanto ${ }^{3}$ \\ 1,2,3Program Studi Teknik Informatika \\ 1,2,3 Sekolah Tinggi Teknologi Muhammadiyah Cileungsi \\ J1. Anggrek No. 25 Perum PTSC, Kec. Cileungsi, Kab. Bogor Jawa Barat 16820 \\ Email: olisvcmc@yahoo.com ${ }^{1}$, priasukamto@gmail.com², \\ mr.siswanto1994@gmail.com ${ }^{3}$
}

\begin{abstract}
ABSTRAK
Sebagai pendidik profesional dan ilmuwan dosen bertugas mentransformasikan, mengembangkan dan menyebarluaskan ilmu pengetahuan teknologi dan seni melalui pendidikan, penelitian dan pengabdian masyarakat sesuai perundang-undangan pendidikan nasional. Namun pada kenyataanya masih banyak dosen sebagai tenaga pendidik profesional itu tidak melakukan tridarma sesuai peraturan perundangundangan tersebut. Dalam mengukur kinerja setiap dosen supaya sesuai dengan yang disyaratkan tersebut maka perlu suatu metode bahwa dosen yang bersangkutan termasuk pada kriteria dosen baik atau kurang baik. Dalam mengetahui permasalahan diatas penelitian ini bertujuan bagaimana mengukur kinerja dosen menggunakan aplikasi sistem pendukung keputusan atau support system untuk menentukan kriteria dosen terbaik menggunakan metode Simple Additive Weighting (SAW) dalam impelementasinya sistem pendukung keputusan menggunakan server Localhost Xampp dan Database MySql. Dengan sistem pendukung keputusan ini diharapkan dapat membantu manajemen perguruan tinggi dalam menentukan kinerja dosen.
\end{abstract}

Kata kunci : SAW, Support System, Database

\section{ABSTRACT}

As professional educators and scientists, lecturers are tasked with transforming, developing and disseminating technological and artistic knowledge through education, research and community service in accordance with national education legislation. However, in reality there are still many lecturers who are professional educators who do not practice tridharma according to the laws and regulations. In measuring the performance of each lecturer so that it is in accordance with these requirements, a method is needed that the lecturer concerned is included in the criteria for good or poor lecturers. In knowing the above problems, this study aims to measure the performance of lecturers using a decision support system application or support_system to determine the criteria for the best lecturers using the Simple Additive Weighting (SAW) method in implementing a decision support system using the Localhost Xampp server and MySql database. With this decision support system, it is hoped that it can help higher education management in determining lecturer performance.

Keywords: SAW, Support System, Database. 


\section{PENDAHULUAN}

Dosen merupakan pilar utama dalam institusi pendidikan tinggi dan kualitas dosen sangat mempengaruhi kualitas institusi tersebut. Selain tridharma, dosen juga harus melakukan tugas penunjang lainnya. Dosen yang aktif dalam kegiatan tridharma akan meningkatkan kualitas pendidikan mahasiswa pada institusi tersebut, oleh karena itu sangat penting untuk mengukur kinerja dosen serta mendapat dosen terbaik yang dapat dijadikan motivator bagi mahasiswanya, salah satu cara mengukurnya adalah dengan menggunakan Sistem Pendukung Keputusan.

Sekolah Tinggi Teknologi Muhammadiyah Cileungsi adalah Perguruan Tinggi Swasta yang terdapat di PTSC Cileungsi Bogor, yang selalu berupaya dalam peningkatan mutu internal secara berkelanjutan agar dapat bersaing dengan perguruan tinggi lainnya. Salah satu upaya yang belum pernah dilakukan adalah dengan melakukan penilaian terhadap kinerja dosen. Maka dari itu dibuatnya Sistem Pendukung Keputusan guna untuk mencari kandidat dosen terbaik dari yang baik lainnya dan dapat juga sebagai penilaian ketua kampus untuk melihat kinerja para dosen.

\section{METODE PENELITIAN}

Penelitian ini bertujuan untuk membangun sebuah sistem pendukung keputusan, yang berfungsi sebagai alat bantu bagi manajemen perguruan tinggi dalam menentukan kriteria dosen terbaik. Agar tujuan SPK ini dapat berhasil dengan baik, maka dibantu dengan menggunakan salah satu metode pengambilan keputusan yakni, Simple Additive Weighting (Sonata, 2016).

SAW suatu tool untuk menentukan metode penjumlahan terbobot. Konsep dasar metode SAW adalah mencari penjumlahan terbobot dari rating kinerja pada setiap alternatif dari semua atribut (Frindo, 2018). Dalam metode ini dibutuhkan proses normalisasi yang berbentuk matrik keputusan (x) skala pembanding dengan semua rating alternatif yang ada. Adapun metode penelitian yang dijelaskan gambar 1 . 


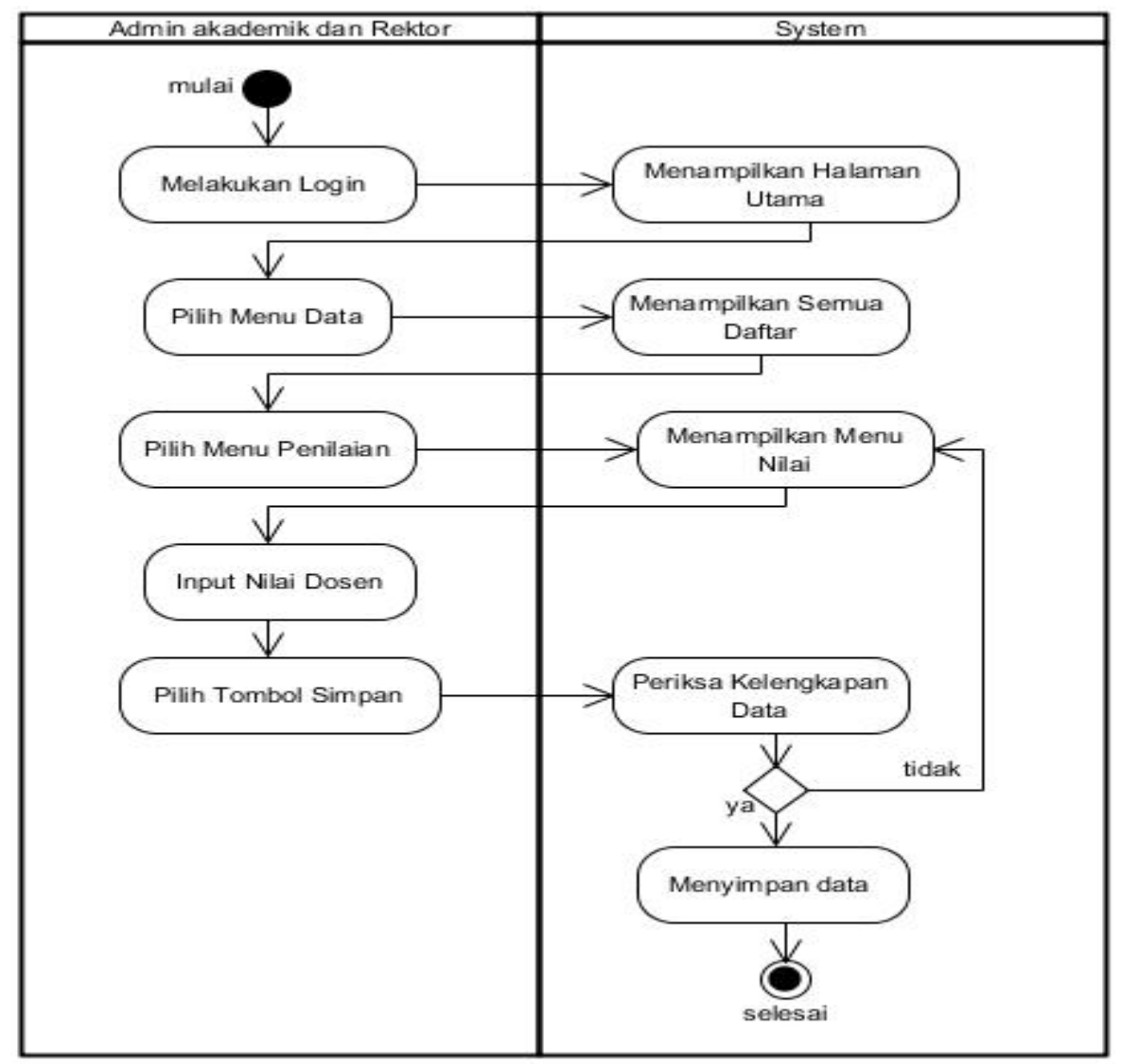

Gambar 1: Diagram Penilaian Akternatif Dosen

\subsection{Dosen}

Dosen adalah pendidik profesional dan ilmuwan dengan tugas utama mentransformasikan, mengembangkan, dan menyebarluaskan ilmu pengetahuan, teknologi, dan seni melalui pendidikan, penelitian, dan pengabdian kepada masyarakat (Firman, 2014).

\subsection{Sistem}

Sistem ialah suatu jaringan kerja yang terbentuk dari prosedur-prosedur yang saling terkait dan terhubung dalam melakukan suatu tugas secara bersama dalam mencapai suatu tujuan (Firman, 2014).

\subsection{Multiple Attribute Decision Making (MADM)}

Menurut (Yogiyanto, 2014), Multiple Decision Making suatu metode dalam mencari beberapa alternatif dari berbagai alternatif dari kriteria tertentu. MADM suatu 
metode untuk menentukan nilai bobot setiap atribut, kemudian dilakukan perangkingan dalam proses seleksi alternatif yang diberikan (Frindo, 2018).

\subsection{Sistem Pendukung Keputusan}

Suatu sistem pendukung keputusan adalah sistem yang bisa mendukung pekerjaan seorang menajer maupun sekelompok manajer dalam memecahkan masalah-masalah terstruktur dengan cara memberikan usulan atau informasi dalam menentukan suatu keputusan (Kurniawansyah, dkk, 2019)(Marbun, 2018).

\subsection{Simple Additive Weighting}

Simple Additive Weighting suatu metode penjumlahan terbobot (Kusumadewi dan Hartati, 2016). Sehingga dengan demikian metode SAW ini memiliki mengenal dua atribut yaitu kriteria manfaat (benefit) dan kriteria biaya (cost) (Ladjamudin, 2013).

\subsection{Proses Perhitungan}

Proses perhitungan metode SAW meliputi beberapa langkah, berikut di bawah ini langkah-langkah perhitungan dengan SAW sebagai berikut(Linda, 2016),(Ibrahim dan Surya, 2019).

1. Penentuan alternatif yaitu (Ai)

2. Penentuan kriteria yang menjadi acuan dalam pengambil keputusan $(\mathrm{Cj})$.

3. Penentuan nilai rating pada kecocokan untuk setiap alternatif pada setiap kriteria

4. Penentuan bobot preferensi (W) pada setiap kriteria

5. $\mathrm{W}=[\mathrm{W} 1, \mathrm{~W} 2 \ldots, \mathrm{Wj})$.

6. Penentuan tabel rating kecocokan dari setiap alternatif pada setiap kriteria

7. Penentuan matrik keputusan $(\mathrm{X})$ yang terbentuk dari tabel rating kecocokan dari setiap alternatif pada setiap kriteria. Untuk nilai (x) pada setiap alternatif (Ai) pada setiap kriteria $(\mathrm{Cj})$ yang sudah ditentukan, dimana parameter $\mathrm{i}=1,2, . . \mathrm{m}$ dan

$$
X=\left[\begin{array}{cccc}
x_{11} & x_{12} & \ldots & x_{1 j} \\
\cdot & & \cdot \\
\cdot & & \cdot \\
x_{i 1} & x_{i 2} & \ldots & x_{i j}
\end{array}\right]
$$

parameter $\mathrm{j}=1,2 . . \mathrm{n}$. 
8. Lakukan normalisasi matrik keputusan dengan cara menghitung nilai rating kinerja ternormalisasi (rij) dari alternatif Ai pada kriteria $\mathrm{Cj}$.

$$
r_{i j}= \begin{cases}\frac{x_{i j}}{\operatorname{Max}_{i j}} & \text { Jika j adalah atribut keuntungan (benefit) } \\ \prod_{i}^{\operatorname{Min}_{i j}} & \text { Jika j adalah atribut biaya (cost) }\end{cases}
$$

Keterangan:

a. Kriteria keuntungan (benefit) yaitu apabila nilai Xij memberikan keuntungan bagi pengambil keputusan. Sebaliknya kriteria biaya apabila Xij menimbulkan biaya bagi pengambil keputusan.

b. Apbila merupakan kriteria keuntungan maka nilai Xij dibagi menjadi nilai maxi (Xi) dari setipa kolom, sedangkan untuk kriteria biaya nilai Mini (Xij) dibagi dari setiap kolom menjadi nilai Xij.

9. Hasil perhitungan nilai rating kerja ternormalisasi (rij) membentuk matrik ternormalisasi(R).

$$
R=\left[\begin{array}{cccc}
r_{11} & r_{12} & \ldots & r_{1 j} \\
\cdot & & \cdot \\
\dot{r_{i 1}} & & & \cdot \\
r_{i 2} & . & \dot{r_{i j}}
\end{array}\right]
$$

10. Hasil akhir dari nilai preferensi (Vi) diperoleh dari hasil penjumlahan dari perkalian elemen baris matrik ternormalisasi (R) dengan bobot preferensi (W) yang bersesuaian dengan elemen kolom matrik (W).

$$
V_{i}=\sum_{j=1}^{n} W_{j} r_{i j}
$$

Selanjutnya hasil perhitungan nilai Vi yang lebih besar mengindikasikan bahwa hasil dari alternatif Ai adalah alternatif terbaik. Setelah itu melakukan perangkingan dengan cara mengalihkan nilai SAW dengan nilai indikasi, dan hasil akhir dari nilai akan dirangking dari urutan yang paling besar sampai yang terkecil. 


\section{HASIL DAN PEMBAHASAN}

Penggunaan aplikasi sistem pendukung keputusan dalam penentuan kriteria dosen dengan kinerja terbaik menggunakan metode Simple Additive Weighting(WAP) hanya berfungsi dalam melakukan perhitungan guna menentukan kinerja dosen terbaik dari yang terbaik lainya. Pada proses ini yaitu untuk melakukan perhitungan dengan cara, mengisi kuesioner kemudian memasukkan data kuesioner yang diperoleh ke dalam sistem, kemudian sistem melakukan perhitungan sesuai dengan metode yang ditentukan yaitu metode SAW, sehingga didapatkan data berupa perangkingan kemudian didapatlah yang namanya peringkat dosen yang diharapkan.

\subsection{Perangkat Lunak dan Perangkat Keras}

Pada tahap implementasi ini perangkat keras dan perangkat lunak yang penulis gunakan dengan spesifikasi.

a. Perangkat Lunak Perangkat Lunak

- Operating System : Windows 7 Ultimate 32-bit

- Bahasa Pemrograman : PHP.

- Database : MySQL, Code Editor : Sublime Text dan Apache XAMPP.

b. Perangkat Keras

- Processor AMD Dual Core E1-1200 1.4GHz

Dengan spesifikasi perangkat keras dan perangkat lunak seperti di atas tersebut, aplikasi masih sangat bisa berjalan dengan baik.

\subsection{Tampilan Aplikasi}

Aplikasi system pendukung keputusan menentukan kriteria dosen terbaik dengan SAW berbasis web ini dapat berjalan secara online maupun offline dari hasil dari implementasi sistem.

\subsubsection{Halaman Login}

Ketika aplikasi pertama kali dibuka tampilan pertama halaman login, selanjutnya pnegguna diminta memasukan nama user dan password dimana data tersebut sudah tersimpan di database sistem, jika user dan password tidak sesuai maka sistem kan 
melakukan feedback bahwa user dan password tidak sesuai, jika user dan password sesuai maka akan ditampilkan halaman utama dari aplikasi.

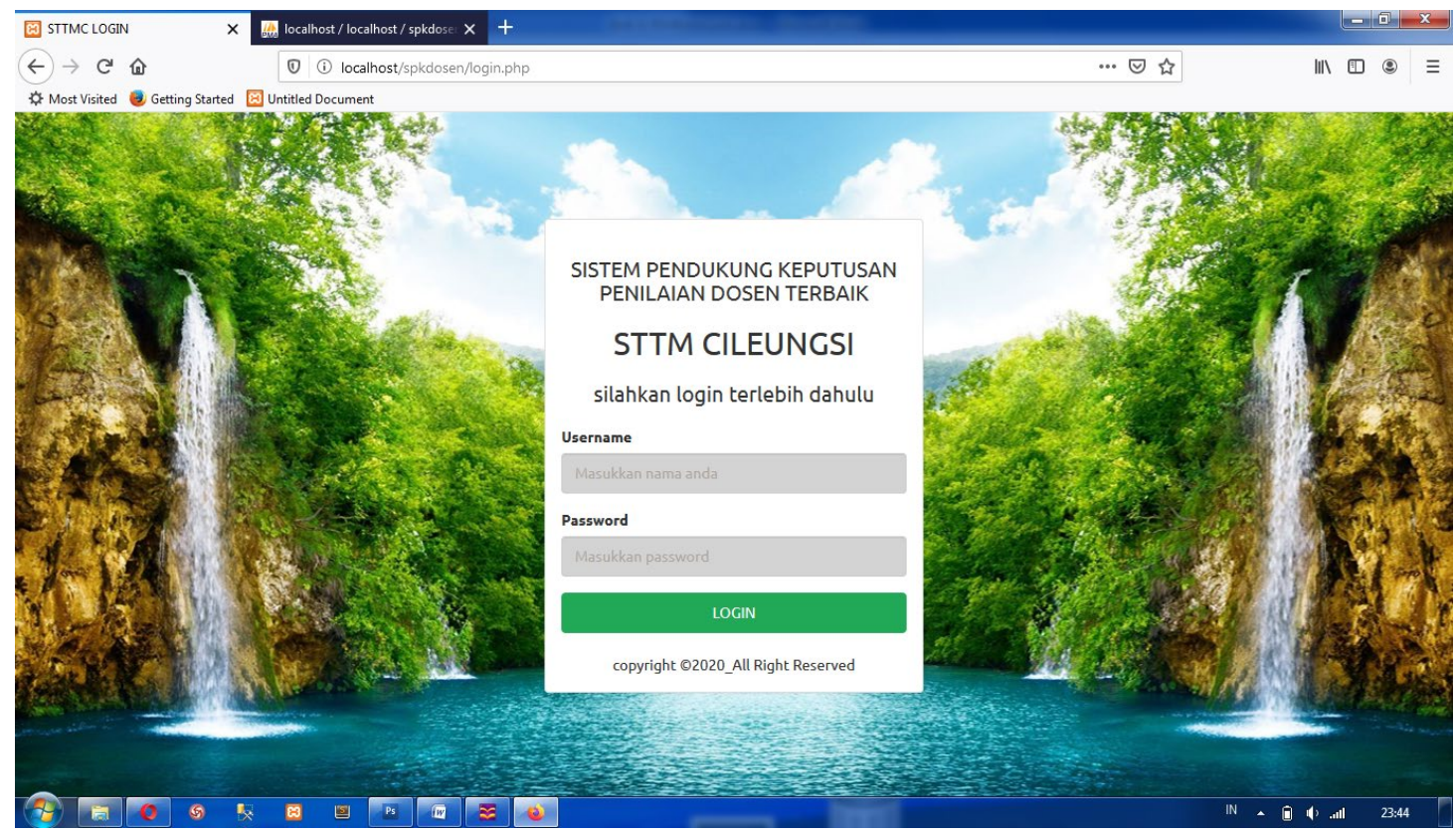

Gambar 2: Halaman Login

\subsubsection{Halaman Beranda Utama}

Setelah pengguna berhasil masuk maka system akan menampilkan halaman beranda utama, pada halaman ini menampilan form home admin menampilkan halaman utama yang menjadi hak akses admin. Pada form home admin menampilkan header, section dan footer. Pada header menampilkan beberapa menu yang setiap menu terdiri dari menu home, input, data, laporan dan online. Pada section menampilkan teks Sistem Pendamping Keputuasn Menentukan Kriteria Dosen Terbaik di Sekolah Tinggi Teknologi Muhammadiyah Cileungsi dengan Metode Simple Additive Weighting" dan Footer menampilkan teks copyright. 


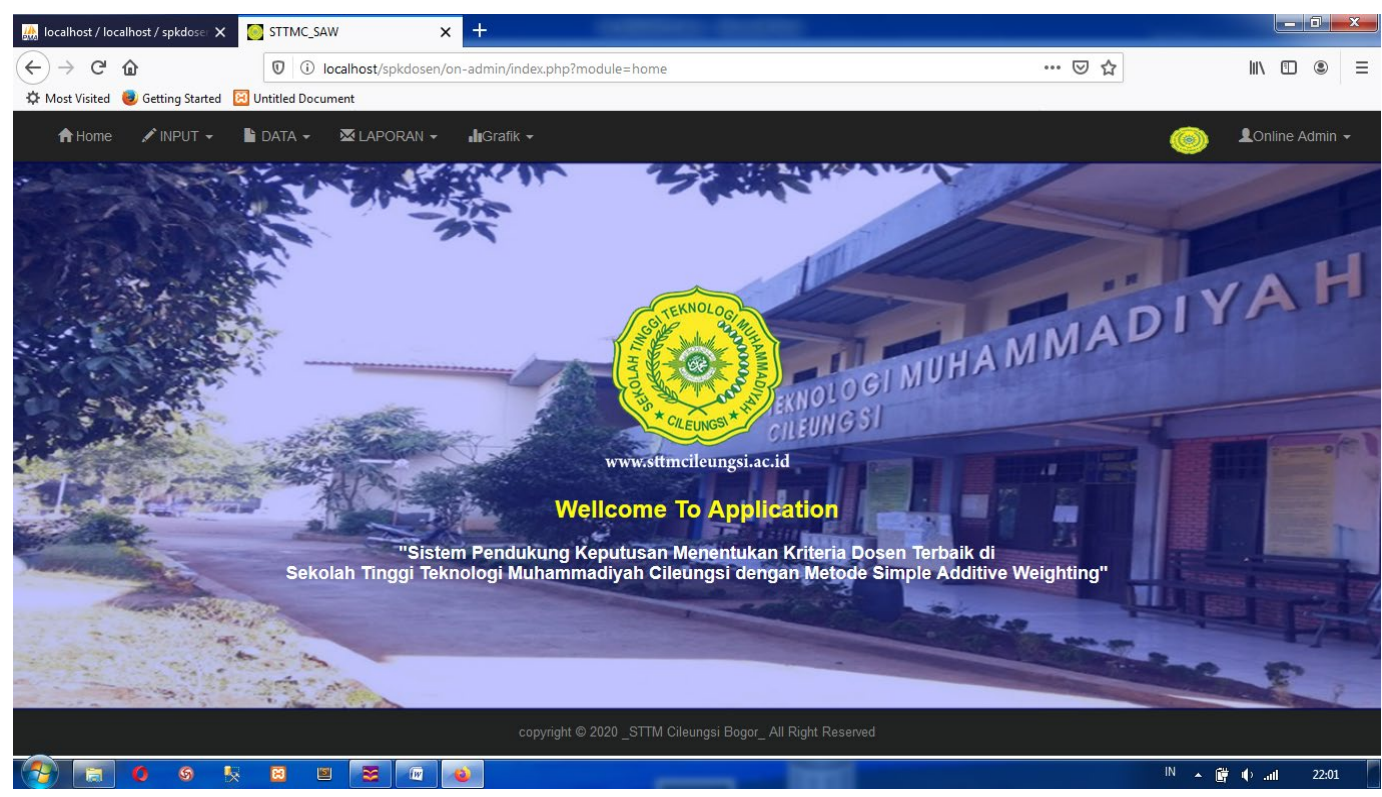

Gambar 3: Beranda Utama

\subsection{Pengujian Sistem}

Untuk mengetahui fungsi dan kualitas dari perangkat lunak yang telah dibangun diperlukan pengujian perangkat lunak. Dalam pengujian perangkat lunak menggunakan standar ISO 9126.

Adapun pengujian ada 20 pertanyaan dan 5 alternatif jawaban dengan menggunakan skala likert dengan perhitungan.

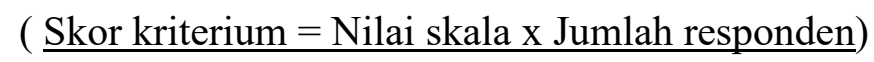

A. Perhitungan nilai presentase dari skor hasil pengumpulan data untuk faktor fungsionality

- Jumlah skor hasil pengumpulan data $=351$

- Jumlah Jawaban dari 20 responden $=100$

- Nilai rata-rata $=\frac{351}{100}=3,51$

- Nilai Presentase $=\frac{3,51}{5} \times 100 \%=70,2 \%$

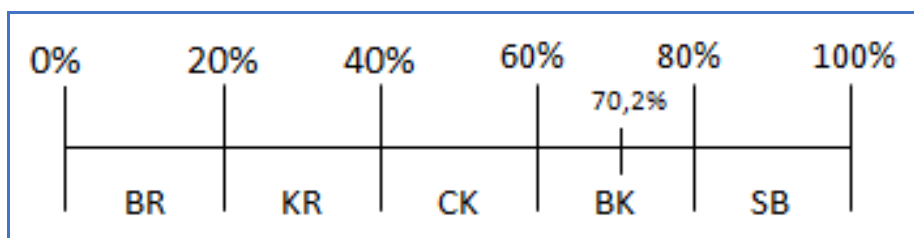

Gambar 4: Skala Likert Hasil Perhitungan Faktor Fungsionality 
Berdasarkan hasil perhitungan faktor fungsionality menghasilkan presentase sebesar $70,2 \%$, sehingga dinyatakan dengan prosentase baik.

B. Perhitungan nilai presentase dari skor hasil pengumpulan data untuk faktor realibility.

- Jumlah skor hasil pengumpulan data $=203$

- Jumlah Jawaban dari 20 responden $=60$

- Nilai rata-rata $=\frac{203}{60}=3,38$

- Nilai Presentase $=\frac{3,38}{5} \times 100 \%=67,67 \%$

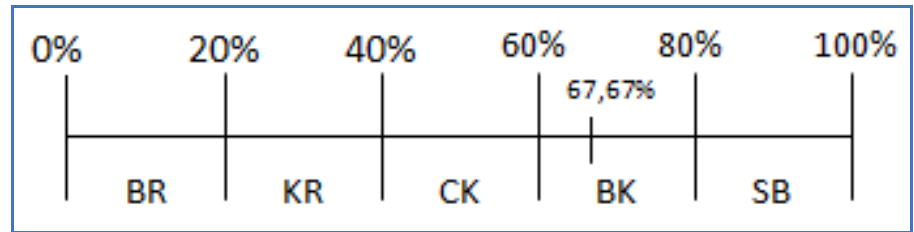

Gambar 5: Skala Likert Hasil Perhitungan Faktor Reliability

Berdasarkan perhitungan di atas faktor reliability memiliki presentase sebesar $67,67 \%$ dengan demikian dapat dinyatakan bahwa skala baik.

C. Perhitungan nilai presentase dari skor hasil pengumpulan data untuk faktor usability.

- Jumlah skor hasil pengumpulan data $=369$

- Jumlah Jawaban dari 20 responden $=100$

- Nilai rata-rata $=\frac{369}{100}=3,69$

- Nilai Presentase $=\frac{3,69}{5} \times 100 \%=73,8 \%$

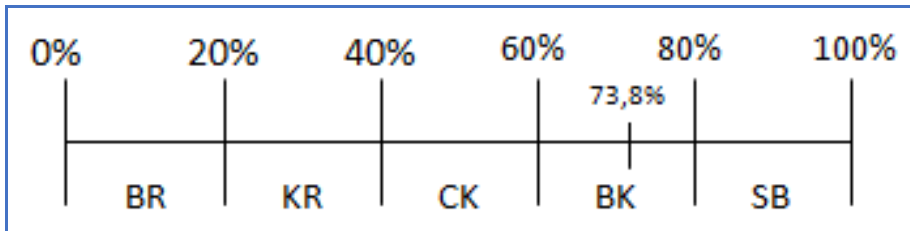

Gambar 6: Skala Likert Hasil Perhitungan Faktor Usability

Berdasarkan perhitungan di atas faktor usability memiliki presentase sebesar 73,8\% dengan demikian dapat dinyatakan bahwa skala baik. 
D. Perhitungan nilai presentase dari skor hasil pengumpulan data untuk faktor efficiency.

- Jumlah skor hasil pengumpulan data $=216$

- Jumlah Jawaban dari 20 responden $=60$

- Nilai rata-rata $=\frac{216}{60}=3,6$

- Nilai Presentase $=\frac{3,6}{5} \times 100 \%=72 \%$

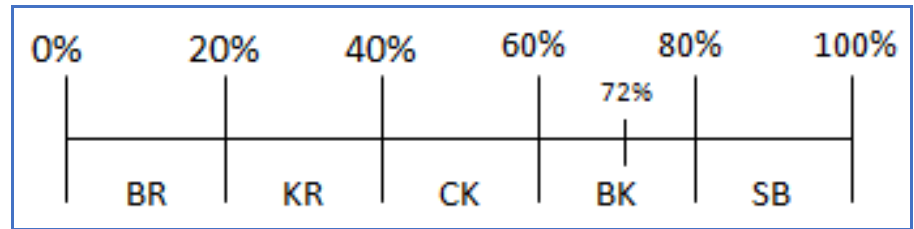

Gambar 7: Skala Likert Hasil Perhitungan Faktor Efficiency

Berdasarkan perhitungan di atas faktor efficiency memiliki presentase sebesar $72 \%$ dengan demikian dapat dinyatakan bahwa skala baik.

E. Perhitungan nilai presentase dari skor hasil pengumpulan data untuk faktor maintainability:

Diketahui :

Jumlah skor hasil pengumpulan data $=140$

Jumlah Jawaban dari 20 responden $=40$

Nilai rata-rata $=\frac{140}{40}=3,5$

Nilai Presentase $=\frac{3,5}{5} \times 100 \%=70 \%$

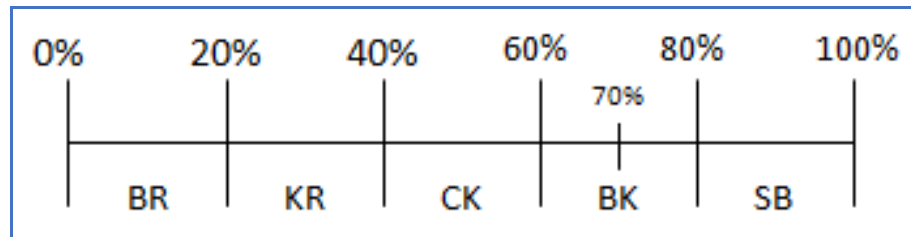

Gambar 8: Skala Likert Hasil Perhitungan Faktor Maintainability

Berdasarkan perhitungan di atas faktor maintainability memiliki presentase sebesar $70 \%$ dengan demikian dapat dinyatakan bahwa skala baik. 
F. Perhitungan nilai presentase dari skor hasil pengumpulan data untuk faktor portability.

- Jumlah skor hasil pengumpulan data $=142$

- Jumlah Jawaban dari 20 responden $=40$

- Nilai rata-rata $=\frac{142}{40}=3,55$

- Nilai Presentase $=\frac{3,55}{5} \times 100 \%=71 \%$

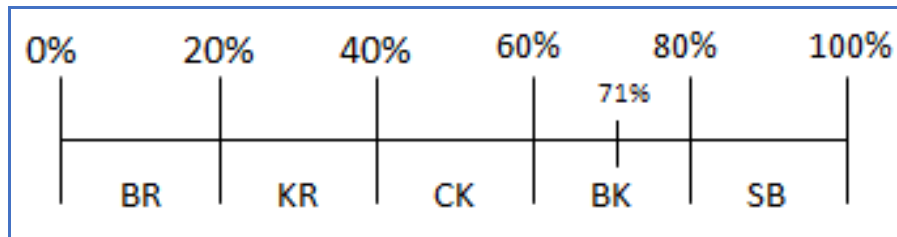

Gambar 9: Skala Likert Hasil Perhitungan Faktor Portability

Berdasarkan perhitungan di atas faktor portability memiliki presentase sebesar $71 \%$ dengan demikian dapat dinyatakan bahwa skala baik.

\section{SIMPULAN}

Proses pemilihan kriteria dosen terbaik dengan menggunakan metode Simple Additive Weighting(SAW) dapat mengolah kriteria-kriteria dosen sehingga menghasilkan dosen dengan konerja terbaik, setelah dilakukan perancangan dan pengujian fungsionalitas dengan ISO 9126 menghasilkan performance 70,2 \% dikategorikan baik. Sehingga dengan adanya sistem pendamping keputusan ini bisa sebagai alat bantu dalam mengevalusi kinerja dosen sebagai pendidik profesional dalam melakukan tridarma perguruan tinggi, selanjutnya bagi manajemen perguruan tinggi dalam penentuan dosen terbaik. Sebagai saran dari penulis untuk perbaikan penelitian selanjutnya yaitu: 1) Diharapkan menggunakan metode perhitungan sistem pendukung keputusan yang lainnya. 2) Dapat digunakan dan dikembangkan sebagai penilaian dosen di Sekolah Tinggi Teknologi Muhammadiyah Cileungsi.

\section{DAFTAR PUSTAKA}

Destiningrum M dan Adrian J, "Sistem Informasi Penjadwalan Dokter Berbasis Web dengan Menggunakan Framework Codeigniter," J. TEKNOINFO, vol. Vol. 11, N, pp. 30-37. ISSN 1693 0010, 2017. 
F. Sonata, "Implementasi Metode Simple Additive Weighting (Saw) dengan Proses Fuzzifikasi dalam Penilaian Kinerja Dosen," J. Teknol. Inf. dan Komun., vol. 5, no. 2, pp. 71-80, 2016.

M. M. Frindo, "Sistem Penunjang Keputusan dalam Evaluasi Kinerja Karyawan Menggunakan Metode SAW pada PT. Sierad Produce," J. Inform. Univ. Pamulang, vol. 3, no. 1, p. 13, 2018.

A. Firman, "Sistem Informasi Perpustakaan Online Berbasis Web," (E-Journal)Teknik Elektro dan Komput., vol. vol.5 no.2, no. ISSN 2301-8402, 2016.

M. Yogiyanto, Analisis dan Desain Sistem Informasi. Yogyakarta: Andi offset Yogyakarta, 2014.

Kurniawansyah and Dkk, "Membangun SPK untuk Menentukan Dosen Berprestasi di Prodi Informatika,” J. Media Infotama, vol. Vol.15, no. No.1, 2019.

S. B. Marbun M, "Sistem Pendukung Keputusan Penilaian Hasil Belajar dengan Metode Topsis," 2018.

H. A. dan W. R. Kusumadewi, S, Hartati S, Fuzzy Multiple Attribute Decision Making. Yogyakarta: Graha Ilmu, 2006.

A. Ladjamudin, Analisis dan Desain Sistem Informasi. Yogyakarta: Graha Ilmu, 2013.

D. Linda, "Merancang e-katalog Berbasis Website Sebagai Media Informasi pada Badan Perpustakaan Arsip dan Dokumentasi Daerah (BPAD) Lampung," J. Sist. Inf. dan Telemat. ISSN 2087-2062, 2016.

A. Ibrahim and R. A. Surya, "The Implementation of Simple Additive Weighting (SAW) Method in Decision Support System for the Best School Selection in Jambi," J. Phys. Conf. Ser., vol. 1338, no. 1, 2019. 